\title{
Aspects of Psychoaffective Development of Children Hailing from Divorced or Separated Parents in Urban and Periurban Areas: A Case Study from the City of Cotonou
}

\author{
Chantal Gahou Assogba*, Emilie Fiossi Kpadonou, Clarisse K. Napporn, Anselme Djidonou \\ Doctoral School of Psychology and Educational Sciences, University of Abomey-Calavi, Abomey-Calavi, Benin \\ Email: *chantou.gahou@gmail.com
}

How to cite this paper: Assogba, C. G., Kpadonou, E. F., Napporn, C. K., \& Djidonou, A. (2021). Aspects of Psychoaffective Development of Children Hailing from Divorced or Separated Parents in Urban and Periurban Areas: A Case Study from the City of Cotonou. Psychology, 12, 887-898.

https://doi.org/10.4236/psych.2021.126054

Received: April 20, 2021

Accepted: June 18, 2021

Published: June 21, 2021

Copyright $\odot 2021$ by author(s) and Scientific Research Publishing Inc. This work is licensed under the Creative Commons Attribution International License (CC BY 4.0).

http://creativecommons.org/licenses/by/4.0/

\begin{abstract}
Instances of divorce or separation have consequences on the psychoaffective development of children. This article investigates the psychoaffective development of children hailing from separated or divorced families. Using a mixed-methods approach, this study involved 102 participants, with a sampling of children from open and closed care facilities under the auspices of the archdioceses of Cotonou. The analysis of the results obtained confirmed that the aggressiveness and lack of discipline observed in certain children, mostly among boys, can be attributed to the absence of the parents; and those affective deficiencies are expressed through sadness, distress, the taking of narcotics, or depression. Supportive psychotherapy, cognitive-behavioral therapy, and the presence of a fitting substitute for the absent parent are all recommended to ameliorate the psychological wellbeing of such children.
\end{abstract}

\section{Keywords}

Development, Wellbeing, Benin, Children, Divorce, Separation, Resilience

\section{Introduction}

In West African cultures, it is expected that the family provides children with good living conditions, a peaceful emotional climate, security, and socialization. However, some parents may not be able to assume this responsibility, and some may even ignore the consequences that this lacuna may have on children. Today, the family, with its instability, reduced size, and the frequent absence of one of the parents from the family home, may explain certain psychological imbalances noted in some children from separated households. 
These shortcomings in the development of the personality of many young people today illustrate the importance of the family's furnishings of positive reinforcements to the child in order to help him or her reach the proper adult dimensions. In order to ensure the education of children, the family, the basis of society, remains the first place where true education begins, thus allowing for an ideal and adequate psychomotor development of the child. A proper environment allows the child to have harmonious growth, especially if he or she receives a good education from the parents. But it often happens that some couples lose harmony and find themselves in conflicts or even quarrels, which end up destabilizing them. In such destabilized families, the absence of one of the parents can deprive the child of material and social security, not to mention the affection of the absent parent, which is necessary for somatic, psychological, and emotional development. Following the proposition advanced most notably by (Liberman, 1984), it is the position of this paper that the emotional security that governs the child's future comes from the emotional quality of her or his family environment. This investigation analyzed the aforementioned phenomena concerning children's psychoaffective development using a sample study from the city of Cotonou, Benin. The choice of this subject was undertaken in the main due to observations in daily experience, that is, of children whose parents were separated either by divorce, death, travel, or for many other reasons. We have found that many of these children find themselves in difficult situations and sometimes develop behavioral problems. This supposition was corroborated by close proximity to them, upon noticing that the majority of children received are victims of their parents' separation and other associated problems.

\section{Theoretical and Methodological Frameworks}

Any study of the psycho-emotional development of children of separated parents requires the development of a theoretical framework of research that would allow the problem to be clearly articulated. This section, therefore, presents the research issue followed by the objectives and hypotheses of the research, a clarification of the concepts, and a review of the literature.

In the Republic of Benin, the percentage of divorced, widowed, separated and common-law couples is $6.17 \%$, according to the fourth General Census of Population and Housing of 2013. Children hailing from single parent families sometimes go through the stages of development with challenges and present psycho-emotional difficulties. It is in the face of this observation that it was decided to explore the development of children from single-parent families, in order to propose ways to ensure an environment where there would be a climate conducive to their fulfillment and psycho-emotional development. The great upheaval of separation has been testified to by (Sanguet, 2014), who observes that "The separation of the parents affects the children (in a way that) it is difficult for a child not to think that it is there for something, not to blame one or the other, not to feel torn between these two people he loves." 
The frequent absence of parents is a phenomenon that ruins psychological balance, disturbs the affectivity of the child, and, even more still, that of the adolescent and the adult. The absence of a parent immediately immerses the child in a state of emotional deprivation, which is the source of the later problem of abandonment neurosis. Whereas a healthy child would have been brought up in conditions, that could help her or him to eventually acquire freedom and independence, children who are separated from one of their parents, or deprived of their parents' protection and security, sometimes become vulnerable to various forms of exploitation and abuse. In this research, we have found that many children in such difficult circumstances do indeed come from separated families. They inevitably encounter psychological suffering. Children are sometimes left to fend for themselves, where they become easy prey to disease, malnutrition, school failure, and even juvenile delinquency. Children from separated families sometimes become victims of economic exploitation, augmenting the number of children on the streets and in markets.

Divorce or separation of the couple does not arise from one particular situation. But in the majority of cases, it is the result of "progressive disunity". That is to say, gradually, communication fades within the couple, and monotony and boredom appear. Eventual separation constitutes for some children a trauma, making them also vulnerable. According to Aguilar and (Aguilar \& Galbes, 2002), "Conjugal harmony is essential for maintaining family cohesion and this is fundamental for the good psychosocial development of children. Children and adolescents are human beings in the growth phase; their personality is not yet fully structured. And to achieve a solid structure, you need the support and example of a united home." (Petitclerc, 2005), for his part, posits that the age factor at the time of separation can be decisive for the child. It appears that the younger the child, the more traumatic the divorce or separation can be, as their level of understanding of the problems is less sophisticated, as is their ability to express their feelings about it appropriately. It should also be noted in that vein that the most important period in the life of any individual on the psychological level is during the first two years of life see also (Cohen-Solal, 1982; Sillamy, 1995).

For this study, the observations of children from separated and single-parent families were carried out at the National Psychiatric University Hospital Center of Jacquot, at the Center for Applied Medical, Psychological, and Social Research, and at the Crossroads Listening and Orientation Center. The various observations undertaken there enabled an assessment of the physical, moral, and psychological suffering of children in this category, and the undertaking of a deep reflection on their psycho-emotional and relational development.

\section{Goals of the Research}

In order to work toward the well-being and alleviation of the suffering of children in difficult situations, this research identifies aspects of care that must be prioritized in the case of children in difficult situations in general, and of child- 
ren of separated or single-parent families in particular. All throughout, the goals are as follows: to analyze the consequences of the couple's separation on the psycho-emotional development of children in urban and periurban areas; to articulate the consequences of the disturbances on the psycho-emotional welfare of the children; and to identify the means by which the children's situation might be ameliorated.

The preliminary hypothesis under which the findings presented are that, firstly, the separation of the couple is likely due to misunderstanding, disrespect, the incompatibility of the two partners, or, in some cases, the death of one of the spouses; emotional disturbances stemming from separation lead most of the children surveyed to anxiety or drug addiction; and that information, awareness, and support will contribute to better psychological care that can help to overcome the disruption of separation.

At this juncture, it is useful to showcase how (Chaplier \& Crosnier, 2014) speak of psychoaffective autonomy. These authors define it as being the capacity of each individual to know him or herself in order to regulate emotions and subsequently take responsibility for personal choice. Within the framework of this research, and building on the scholarship mentioned above, "psychoaffective" shall convey the whole of the mental processes pertaining to the emotional and affective system occurring in early childhood, including the emotional relationships maintained in the event of divorce or the separation of parents, on the psychological development of children.

Also relevant are the repercussions upon the internal working model, which is a cognitive framework that includes mental representations used to understand the world, the self and others. A person's interaction with others is guided by memories and expectations of their internal model that influence and help to assess their contact with others. At three years of age, the internal model seems to transform into part of a child's personality. Therefore, it affects the child's understanding of the world and future interactions with others.

Affectivity, as it is understood in this investigation, is the realm of emotions and feelings. Affective development is a long series of more or less conflicting experiences, between the subject and those in the immediate environment, but also within the subject. Thus, according to (Lorin, 2009), psycho-emotional or affective development means that the child manifests many emotions, from sadness to joy to anger, and learns to express them.

\section{Previous Relevant Scholarship and Theoretical Perspective}

In addition to the sources and thematic/theoretical categories mentioned above, this study has been grounded in a myriad of relevant preexisting scholarly perspectives and prisms, all of which may be useful for related inquiry. The following are but limited examples of such sources. Other relevant sources are cited throughout the paper.

(Bandura, 1986) social-cognitive theories on the management of emotions 
have been particularly instructive, especially with regard to the variables related to behavioral factors; environmental (extrinsic) factors; and personal (intrinsic) factors. Similarly, notions have been adopted from systems theory (von Bertalanffy, 1968), a multidisciplinary approach that studies the common properties in many entities, and which is particularly effective in the field of social relations, such as the family system, the associative system, the local exchange system, etc.

With regard to perspectives on children's development and clinical work with young children's psyches, different conceptual models have been especially influential. These include the models proposed by (Klein, 1968), (Piaget 1969), (Mahler, 1975), and (Gardner, 1998). The work of (Winnicott, 1931, 1957), who was among the first to link childhood traumatic separations to delinquent behaviors that occur later, was paramount. The recognition of forms of depression in the work of authors such as (Spitz, 1945), (Aubry 2003), and (Bowlby 1969, 1973,1980 ) have been foundational, especially regard to the last author, whose theories help us to understand how the separation or divorce of parents has a strong influence on the psycho-emotional development of children, especially if it occurs at a very young age.

\section{Methodology}

This work was carried out in several different locales under the auspices of the Service of Charity for Integral Human Development, under the umbrella of the archdioceses of Cotonou. Registered with the Beninese government, they are all social and humanitarian entities, functioning as private centers that absorb children in difficult situations.

The target population for the study consisted of children from divorced or separated parents under the care of these centers. The age of the children was between 10 and 18 years old. The study dealt with children of both sexes. Parents (divorced or separated), as well as center managers, were also engaged. Proper permissions for human subject research were obtained from the relevant authorities all throughout.

Children were chosen through referrals. 102 subjects were identified and selected to participate in the interviews. The resource persons were selected according to our preference, the criteria for choice being essentially related to their practical experience on the issue at hand, such as lived experience and on the basis of their knowledge of the psychological consequences of divorce or separation. We questioned 10 people (6 men and 4 women) in this category. A total of 112 subjects were identified and investigated as part of this research.

The chosen methodological approach was mixed-methods, combining both quantitative and qualitative variables. The quantitative aspect allowed for the measurement of the extent of the phenomenon and the plurality of emotions and feelings it implies. The qualitative aspect allowed for documentary research, the use of the survey questionnaire, and the semi-structured interview format, all of which enabled the collection of the children's life stories. 
The survey questionnaire used with the 102 children was necessary for the production of measurable information with this target. It consisted in formulating open and closed questions according to the specific objectives stated above. The variables studied were linked to age, sex, level of education, and emotional deprivation as perceived (shyness, anxiety, insecurity, aggression). To be able to properly analyze the unspoken sentiments of the children observed during the interviews, an observational categorization was developed in terms of the following: depressed mood; anxious behavioral problems; feelings of isolation; folds of skin appearing on the forehead; and agitation.

\section{Presentation and Analysis of Results}

Table 1 shows a high number of children in the 15 to 18 age group (42.18\%). This is followed by children aged 12 to $15(35.29 \%)$ and then those aged 10 to 12 (23.53\%). It is significant that the number of children aged 12 to 15 and 15 to 18 is greater than that of children aged 10 to 12 . In this adolescent period, the individual begins to ask questions about her/his identity, belonging, and the transformations $\mathrm{s} / \mathrm{he}$ observes in the body. When $\mathrm{s} / \mathrm{he}$ discovers that things a parent had said about her/his identity was not true, $s /$ he feels insecure and sometimes takes on this parent as an opponent. This is certainly what justifies the fact that it is the children of these groups who are numerous in the care centers. However, it can be said that separation or divorce affects children regardless of their age from birth to adulthood or beyond.

It is worthy to note here that the percentage of girls exceeds that of boys (Table 2). This could be explained by the fact that girls, in light of the data, are more vulnerable to be affected by the separation of parents. Also, in light of financial difficulties and parents eventually remarrying (other spouses), these girls are sometimes placed in care homes. Or, abused or for other reasons, they run away from home and find themselves on the streets, looking for their parents. So that they are not victims of rape that can cause unwanted pregnancies, sexually transmitted infections (STDs) or even HIV/AIDS, they are quickly welcomed in care centers that take care of their education and learning. This is what explains the fact that we met more girls than boys in the centers.

The percentage of boys is due to the fact that when they run away from their families, they are not as lucky to be picked up by reception centers. Rather, they take refuge in the markets, where they fight for their survival. The insecure climate in which they live on the streets means that they do not like to confide. It was only those who attended the centers that served as the framework for our study that we were able to meet such boys.

Table 3 shows a high enrollment of primary school children (45.10\%), followed by the enrollment of those with no education at $31.37 \%$. That is to say, $23.53 \%$ of children surveyed have secondary schooling. Reading this table explains the influence of separation or divorce on children's academic performance. The dropout from school of some of these children is due to the condition 
Table 1. Distribution of children according to age.

\begin{tabular}{ccc}
\hline & N & $\%$ \\
\hline 10 to 12 years & 24 & 23.53 \\
12 to 15 years & 36 & 35.29 \\
15 to 18 years & 42 & 41.18 \\
Total & 102 & 100.00 \\
\hline
\end{tabular}

Source: Field data, 2018.

Table 2. Distribution of children by sex.

\begin{tabular}{ccc}
\hline & $\mathrm{N}$ & $\%$ \\
\hline Female & 62 & 60.78 \\
Male & 40 & 39.22 \\
Total & 102 & 100.00 \\
\hline
\end{tabular}

Source: Field data, 2018.

Table 3. Distribution of children by level of education.

\begin{tabular}{ccc}
\hline & $\mathrm{N}$ & $\%$ \\
\hline Not educated & 32 & 31.37 \\
Primary education & 46 & 45.10 \\
Secondary education & 24 & 23.53 \\
Total & 102 & 100.00 \\
\hline
\end{tabular}

Source: Field data, 2018.

of single parenthood in which certain parents find themselves, especially mothers after separation. The financial resources of the parent who is responsible for the child do not allow the child to pay for school on time or in the long term. On that point, one child said the following:

"I want to continue my studies, but my mother's finances did not allow me to do so. I was always expelled from school, and, being overwhelmed, I went to the market to help the vendors transport their goods in exchange for money. That's how I ended up in this center, thanks to one man [who directed me here]. I want to see my parents together again [in order that they] take better care of me. I miss my parents [...]." (A. N., 14 years old)

This interview excerpt illustrates the educational difficulties of these children and why some children were forced to drop out of classes. Several reasons were mentioned by the children in this regard, chiefly among them, the parents' resignation and indifference to their difficulties; and the challenges inherent in learning after the parents' separation, which led to a lowered academic performance. On the other hand, the parents of some children never had a means of putting them in school. This explains the percentage of children with no level of education-a psychosocial phenomenon in Benin that perpetuates underdevelopment. In a general sense, the instability of children after the separation of 
their parents does not allow them to concentrate on retaining the education given at school. This means that some drop out of school due to insufficient results. To avoid such results, it is recommended that separated parents come to an agreement on how to finance their children's education, in order to ensure a better future for them.

Table 4 shows a higher number of children suffering from emotional deficiency (34.31\%) than from shyness and insecurity. For the children, the parents' separation means that the perception of security has been broken, which makes them suspicious of everyone. Many children suffer from emotional deficiency and expressed it during the interview. All of them were quick to burst into tears (especially the girls), complaining about their situation. So that these moments did not impede the remainder of the interview, it was allowed that they express their emotion, in order that they unload their suffering and begin to eventually rebuild a new image to strengthen their ego. The words of another girl, pointing to her psychological difficulties, are telling in this regard:

"I am often sad and anxious when I am scolded because I feel rejected and I think that this person [doing the scolding] does not love me anymore [...] I feel alone in the world because my parents are not interested in me, otherwise I would not be in this center. I no longer trust anyone because I see that the person could abandon me at any time, especially since the day when my best friend ran away from the center. I no longer have friends, which creates distrust and shyness in me. I wonder if I can ever get married, for fear of being abandoned by a husband, in the same way that my father did to my mother." (V. B., 18 years old)

According to those responsible for the centers, the children they take in are those who, after fleeing from their home for situations of misunderstanding, mistreatment or corporal punishment by their parents or guardians, are found wandering in the streets and in the markets. Likewise, some children in conflict with the law are taken to the Brigade for the Protection of Minors which, in turn, refers them to the reception centers for children in difficult situations. Sometimes, it is the organizers who discover them late at night in front of the shops, begging and waiting for the doors to close in order to lie down at the storefronts. They are taken to reception centers where an attempt is made to find the parents and start family reintegration.

Table 4. Distribution of children according to psychological problems.

\begin{tabular}{ccc}
\hline & $\mathrm{N}$ & $\%$ \\
\hline Insecurity & 21 & 20.59 \\
Stigmatization & 18 & 17.65 \\
Shyness & 28 & 27.45 \\
Affective deficiency & 35 & 34.31 \\
Total & 102 & 100.00 \\
\hline
\end{tabular}

Source: Field data, 2018. 
According to the officials, all of the children received have periods of disturbance. Physical and verbal violence, aggression, instability, and crying without apparent reason are things to be managed daily. The children always feel in a state of dissatisfaction and tend to project onto the adult present the situation of their family, which had caused them to run away. According to the educators at the centers, it is not easy to work with children such as these.

Officials at the centers revealed that some parents are still interested in their children, especially those who had been forced into marriage or into religious sects. However, according to these officials, the parents of children whose are divorced or separated almost never come together to visit their offspring. Usually, only one parent is interested in the child and comes for a visit. This is due to the disagreement which led to their separation. And if it happens that both parents are interested in the child, each wishes to recover the child on their own terms. The child becomes an object of dispute. This state of affairs means that many children no longer want to return to their families and prefer to live in reception centers.

Children cannot find their place within these conflicts, neither in the present, nor in the future. They may feel as if their very existence is in question. This period generates such anxiety that the child will lash out or retreat into isolation. So, on the one hand, we may see behavioral disorders and juvenile crimes, and on the other hand, educational and physical disabilities. This can be explained on a psychological level by the development of a strong narcissistic tendency, which prevents the subject from entering into a stable emotional relationship with others.

It is, therefore, necessary to provide for the substitution of the parental figures, in particular, that of the mother, in the event of death, divorce, or separation of the couple, in order to genuinely help the child to undergo a healthy psycho-emotional development. (For example, long-term consequences of maternal deprivation can include delinquency, reduced intelligence, increased aggression, depression and unaffected psychopathy, which are the inability to show affection or empathy for others. These individuals act impulsively, without thinking of the consequences of their actions, as in the case of not showing guilt after anti-social behavior.) Separated couples need to be aware of this situation in order to prevent their children from sliding into crime, begging, or prostitution, to name just a few possible outcomes. Each family must ensure that the child does not stumble and above all does not fall into drugs.

\section{Conclusions and Implications for Further Research}

Findings from this research point to several significant challenges in psychoaffective development for such children. One major challenge highlighted by this case study is the prevalence of insecurity among children from separated or divorced families. Another is extreme shyness, which was observed through the unspoken communication of the children during the interview sessions. Others 
communicate their dissatisfaction through aggression, tantrums, and crying. All such children may experience denial, grief, a sense of abandonment, loss of self-esteem, anxiety, a feeling of shame, a guilty reaction, or nostalgia for the past combined with a hope that the parents might be reconciled and come back together even if, deep down, such a probability is negligible. The manifestation of various disorders in mood and behavior, depressive or hypomaniacal reactions, academic difficulties, sleep disorders, or various psychosomatic manifestations are all possible, and all the more so the younger the child is. However, it should be noted that following (Lévesque, 1998), the specific reactions and needs of the child are closely linked to the age and stage of development.

Such observations are also apparent in children whose parents have remarried, and when the stepmother or stepfather does not accept such children as their own. This discourages the development of all psychosocial faculties, both in girls as well as in boys. This situation has repercussions on the formation of the ego of the children. Specifically, identification on the part of children is only possible in the presence of the two parents or their functional substitutes who understand the relevance of this decisive stage in the life of the child.

Another factor that plays a major role in the expression of the child's suffering is that of gender. Boys can demonstrate great aggressiveness, which is a factor indicating a poor prognosis. When they are over the age of $6-7$, they may suffer from an overly strong relationship with the mother (who is very often the one who mainly raises the children). To escape from this, the boy may want to stay infantilized, or, conversely, to move toward marginalized groups. Girls, for their part, can completely withdraw into themselves. The seemingly apparent adaptation may in fact reflect great distress. Their risk in adolescence is the appearance of early sexual delinquency.

A number of psychological support mechanisms seem to be prudent as suggestions for support of children in such situations. For example, psychologists can promote dialogue between the parents and the child (in the form of family psychotherapy). They can also call attention to a child's suffering through the identification of symptoms and the detection of early warning signs of depression (anxiety, sadness, behavioral problems, poor academic performance). All throughout, psychologists should encourage the verbalization and the exteriorization of the feelings and emotions of these children in an atmosphere of trust.

Concerning several general recommendations for parents and families, it is suggested that primary caregivers 1) look for ways to reduce daily stress so that children are able to adapt to events in a flexible, effective, and harmonious way; 2) collaborate effectively with the spouse who has custody of the children; 3 ) encourage visits by the non-custodial parent; 4) explain to the children the reasons for the separation or divorce, so as to avoid misunderstandings and/or revolts; and 5) proactively decide about the future of separated children and parents through the intervention of mediating professionals. Those responsible for these children have expressed difficulty in maintaining them due to (among other factors) the fact that some of these children still mourn their parents. Some 
have managed to help them through the reassuring examples of other successful children, while others do not manage to help them, given the difficult personal histories. We suggest to those in charge of the children that more love and attention may help them to fill the emotional void created, in order to promote good mental health. Carrying out such recommendations may move the loss of family relationships away from the most serious consequences, but also, may help to avoid, in the short and long term, the most frequent developmental and personality disorders in children.

\section{Conflicts of Interest}

The authors declare no conflicts of interest regarding the publication of this paper.

\section{References}

Aguilar, I., \& Galbes, H. (2002). Guide de la Vie Familiale. Madrid: Safeliz.

Aubry, J. (2003). Psychanalyse des Enfants Séparés: Etudes Cliniques 1952-1986. Paris: Denoël.

Bandura, A. (1986). Social Foundations of Thought and Action: A Social Cognitive Theory. Englewood Cliffs, NJ: Prentice-Hall.

Bowlby, J. (1969). Attachment. New York: Basic Books.

Bowlby, J. (1973). Attachment and Loss: Separation. New York: Basic Books.

Bowlby, J. (1980). Attachment and Loss: Loss, Sadness, and Depression. New York: Basic Books.

Chaplier, C., \& Crosnier, É. (2014). Dimension et Autonomisation Psychoaffectives dans Deux Dispositifs Hybrides: Etudes de Cas en Master 2. Alsic, 17, 1-28. https://doi.org/10.4000/alsic.2739

Cohen-Solal, J. (1982). Les Deux Premières Années de la Vie, le Prodigieux Éveil de I’Enfant. Paris: Réponses/Robert Laffont.

Gardner, R. A. (1998). The Parental Alienation Syndrome: A Guide for Mental Health and Legal Professionals. Cresskill, NJ: Creative Therapeutics.

Klein, M. (1968). Essais de Psychanalyse (1921-1945) (M. Derrida, Trans.). Paris: Payot.

Lévesque, J. (1998). Méthodologie de la Médiation Familiale. Montréal: Erès.

Liberman, R. (1984). Les Enfants du Divorce. Handicaps et Inadaptations, 26, 24-37.

Lorin, A. M. (2009). Les Étapes du Développement Affectif de l'Enfant, Illustrées de Dessins. https://www.psychiatriemed.com

Mahler, M. (1975). The Psychological Birth of the Human Infant: Symbiosis and Individuation. New York: Basic Books.

Petitclerc, J. M. (2005). Les Nouvelles Délinquances des Jeunes. Paris: Dunod.

Piaget, J. (1969). The Psychology of the Child (B. Inhedler, Trans.). New York: Basic Books.

Sanguet, M. (2014). Quand les Parents se Séparent. Montréal: Erès.

Sillamy, N. (1995). Dictionnaire de la Psychologie. Paris: Larousse.

Spitz, R. (1945). Hospitalism: An Inquiry into the Genesis of Psychiatric Conditions in Early Childhood. Psychoanalytic Study of the Child, 1, 53-74. 
https://doi.org/10.1080/00797308.1945.11823126

Von Bertalanffy, L. (1968). General System Theory: Foundations, Development, Applications. New York: George Braziller.

Winnicott, W. D. (1931). Clinical Notes on Disorders of Childhood. London: Heinneman.

Winnicott, W. D. (1957). The Child and the Family. London: Tavistock. 